\title{
VIGENCIA DE LA METODOLOGÍA VIGOTSKIANA DE LA MOTIVACIÓN DEL APRENDIZAJE
}

\author{
Validity of the vigotskian methodology of learning motivation
}

\author{
Daniel Acosta Mejía \\ Fidel Martínez Álvarez ${ }^{2}$
}

PRESENTACIÓN: 31 DE JULIO DE 2018

APROBACIÓN: 23 NOVIEMBRE DE 2018.

\begin{abstract}
RESUMEN
En este artículo, se desarrolla un detallado análisis de las ideas de L. S. Vigotski para la creación de una emergente metodología de la motivación creativa del aprendizaje de los estudiantes a partir de la utilización de textos pocos conocidos del autor ruso, quien elaboró ideas esenciales para comprender el carácter individual y social complejo de las emociones, instintos humanos, necesidades, intereses, motivaciones, atención, orientación y auto-control. Estos procesos están estrechamente vinculados con el desarrollo de la motivación del aprendizaje en los estudiantes. En concreto, las concepciones de Vigotski tienen gran valor y vigencia para el desarrollo de la labor creativa de los maestros, quienes deben formar y consolidar las bases de esas formaciones psicológicas más comprometidas con la motivación del aprendizaje de los estudiantes.
\end{abstract}

Palabras clave: metodología de la enseñanza, motivación y orientación del aprendizaje y metacognición

\begin{abstract}
In essence, in this article the authors propose developing a detailed analysis of L.S. Vigotski's ideas for the creation of an emerging methodology of the creative motivation of the learning of the students as from the utilization of little-known texts of the Russian genius, who elaborated essential ideas to understand the individual character and social complex of emotions, human instincts, needs, interests, motivations, attention, orientation and self-control, processes narrowly linked to the development of the motivation of the learning in the students. In short, Vigotski's conceptions have great value and validity today for the development of the creative work of the teachers, that they must form and consolidating more engaged the bases of those psychological formations with the motivation of the learning of the students.
\end{abstract}

Keywords: methodology of teaching, motivation and orientation of learning and meta-cognition

1 Licenciado en Educación Física y Deporte por la Escuela Internacional de Educación Física y Deporte de La Habana (2010). Entrenador de Triatlón y metodólogo de Deportes de la Administración Municipal del Municipio de Puerto Gaitán, Departamento del Meta, Colombia. E-mail: petakuciare@gmail.com

2 Doctor en Ciencias de la Educación por la Universidad de la Habana (2011). Máster en Estudios Sociales de la Ciencia y la Tecnología por la Universidad de la Habana (2000). Máster en Filosofía (Kiev, Ucrania, Unión Soviética, 1984). Profesor Titular Adjunto de la Filial de Camagüey de la Universidad de las Artes de Cuba. E-mail: fidelmartinez@nauta.cu 


\section{INTRODUCCIÓN}

Para abarcar por entero el proceso integral de la educación y presentar bajo una luz psicológica todos los aspectos principales de su transcurso es preciso tomar en cuenta también la psicología del trabajo del docente y mostrar a qué leyes está sujeta.

Vigotski, Psicología pedagógica: curso breve [1, p. 489]

En la actualidad, el profesor tiene innumerables retos en el complejo proceso de la formación de sus estudiantes, lo que supone una alta responsabilidad social, tanto en lo relativo a su propia auto-preparación como a la transformación educativa integral de los jóvenes a partir del estudio del entramado complejo de relaciones propias del contexto social particular en el que se desarrolla su vida personal y laboral, así como de las diversas vivencias del grupo de clase. Por tanto, el docente está llamado a encontrar, desde la ciencia, soluciones a esos complejos problemas pedagógicos y sociales con el fin de conducir tanto a cada estudiante como al colectivo al cumplimiento de los objetivos planteados para cada semestre y curso escolar. Hoy reviste más importancia que nunca la sentencia siguiente:

El maestro debe saber estudiar, para que sepa enseñar a estudiar. Aquí está en su germen todo el problema de la pedagogía. Enseñar a trabajar es la tarea del maestro. A trabajar con las manos, con los oídos, con los ojos y después, y sobre todo, con la inteligencia [1, p. 1].

Así, también, la naturaleza compleja y contradictoria de la educación sigue en pie, pues como escribió hace un siglo Vigotski:

Para la educación actual no es tan importante enseñar cierta cantidad de conocimientos, sino a educar la aptitud de adquirir estos conocimientos y valerse de éstos. Y esto se logra únicamente -igual que todo en la vida- en el propio proceso del trabajo y de la conquista del saber [2, p. 491].

En consecuencia, el tema de la motivación, tanto para la superación de los profesores como para el aprendizaje de los estudiantes, constituye hoy en día uno de los más complejos problemas de la educación contemporánea, pues los profesores tienen dificultades organizacionales que limitan tanto su superación profesional como su desempeño laboral cotidiano, entre las cuales sobresalen:

1. El predominio de estilos de dirección de "ordeno y mando" en las instituciones educativas, que limitan la autonomía y la participación creativa de profesores y estudiantes en las transformaciones necesarias en el plano organizacional.

2. Las excesivas cargas docentes con gran cantidad de horas de clases presenciales.

3. El agobiante trabajo burocrático sobrecargado con innumerables reuniones e informes docentes.

Por otro lado, la motivación del aprendizaje de los estudiantes está condicionada por las particularidades psicológicas de los jóvenes, así como por las nocivas influencias de la globalización transcultural y enajenante, impuestas desde las nuevas tecnologías de la información y las telecomunicaciones (TICs), [3], [4], [5], [6], [7], así como la invasión mediática internacional y nacional.

En consecuencia, para el desarrollo de la motivación del aprendizaje de los estudiantes es preciso que los docentes tomen conciencia reflexiva o cumplan con el principio de reflexividad ${ }^{B}$, que, en esen-

3 Las ideas relacionadas con el principio de reflexividad remiten a la aptitud autocrítica del profesor, que debe valorar críticamente su propia labor de enseñanza, además, significa que no es el protagonista ni el interventor, sino solo el facilitador de los procesos de transformación personal y colectiva de los estudiantes para propiciar el proceso de autoorganización del aprendizaje o metacognición. [74, p. 30], [63], [81], [8], [77, p. 125]. 
cia, presupone el proceso bilateral de enseñanza-aprendizaje, así como que dicho proceso constituye un sistema social dinámico complejo, por lo que los profesores tienen que transformarse a sí mismos para poder facilitar la transformación de las actitudes de sus estudiantes.

La enseńanza reflexiva en este proceso fue planteada por J. Dewey quien, en 1929, hacía referencia a que, con la aplicación de este tipo de enseñanza en la formación del profesor, se produce el examen activo, persistente y cuidadoso de todos los elementos que, de una u otra forma, tienen relación con el proceso... Después de J. Dewey, Donald Schön impulsó el desarrollo de esta concepción [63] al proponer que la práctica reflexiva debe estar presente en la formación de profesores [8, p. 21].

Por ello, los docentes deben utilizar varios enfoques, dialéctica y creativamente articulados, desde una concepción o perspectiva más integral de la labor psico-pedagógica del desarrollo de la motivación del aprendizaje de los estudiantes [9]. Ante todo, para alcanzar una perspectiva integradora, es indispensable identificar los diferentes enfoques en la metodología de la motivación, como vía para poder preparar a los profesores en tan compleja labor psico-pedagógica de facilitar la motivación y, más que todo, la auto-organización y auto-motivación de los estudiantes, quienes tienen particularidades psicológicas muy complejas. Por tales razones, "es imprescindible saber qué ocurre en el alumno, cómo aprende ese alumno, qué le interesa saber a ese alumno, ya que es él en última instancia quien determina el éxito o fracaso del proceso de enseńanza - aprendizaje" [10, p. 2].

Actualmente, decenas de autores subrayan la necesidad de buscar nuevas estrategias para la superación profesional [11], [12], [13], [14], pues reviste especial importancia para el desarrollo socioeconómico, político, científico, cultural y educacional de cualquier país. De hecho, hoy más que nunca se necesita elevar el nivel de preparación y actualización epistemológica de los profesores.

Precisamente, en el artículo $1^{\text {o }}$ de la Ley 30 de diciembre de 1992 de la política científica colombiana, se consigna que "la educación superior es un proceso permanente que posibilita el desarrollo de las potencialidades del ser humano de una manera integral”, así como en el artículo $6^{\circ}$ se establece como objetivo "profundizar en la formación integral de los colombianos dentro de las modalidades y calidades de la Educación Superior, capacitándolos para cumplir las funciones profesionales, investigativas y de servicio social que requiere el país" [15]. Además, varios autores colombianos enfatizan esas ideas y otras relativas a la urgencia de elevar el nivel de actualización epistemológica de los profesionales de la educación [16], [17], [18], [19].

Entre los antecedentes teóricos más importantes sobre la motivación del aprendizaje se deben reconocer las ideas de incuestionables precursores como: Vigotski, Piaget, Bateson, Dewey, Ausubel, Galperin, Elkonin, Moreno, Lewin, De Bono, Gardner, Goleman, Serge, entre otros, quienes desde diferentes enfoques y posicionamientos teórico-metodológicos han proporcionado elementos esenciales para encontrar vías didácticas más efectivas, mediante incentivos internos y externos, desplegados por los profesores para favorecer el interés, la motivación e implicación real de los estudiantes en el proceso creativo del aprendizaje.

Un especial significado para el estudio de la motivación del aprendizaje se puede encontrar en las ideas de [20] y [21] sobre las formaciones y configuraciones psicológicas (motivacionales) complejas de la personalidad, las cuales, a su vez, tienen como base los principios vigotskianos de la unidad de lo cognitivo y lo afectivo y de la relación dialéctica de lo interno y lo externo en la situación social del desarrollo [22]. Para estos autores y otros seguidores de la concepción psico-pedagógica históricocultural y constructivista ${ }^{4}$, la motivación constituye un tipo peculiar de elaboración o construcción personal compleja, que relaciona las necesidades, motivos, ideales, intenciones y la auto-valoración, que

4 El constructivismo es uno de los paradigmas emergentes de la integración del saber, que se ha convertido en un vasto movimiento científico e intelectual que está presente en casi todas las formas del saber [35], [67], [80], [64] 
permiten enriquecer las configuraciones subjetivas del individuo, así como las normas, estereotipos, valores y tendencia orientadora de la personalidad. Afortunadamente, ya se está reconociendo, más que nunca, que:

La obra de Vigotski está teniendo hoy día una difusión extraordinaria. Sin duda, la aportación del genial psicólogo ruso viene siendo en las últimas décadas punto de referencia obligado para numerosos autores del ámbito educativo y psicológico, pero también del entorno de la semiología, la crítica literaria y en general de las humanidades y las ciencias sociales [23, p. 8].

Además, a diferencia de algunos autores que afirman que Vigotski no dedicó una obra completa al estudio de las emociones, el Mozart de la psicología escribió un libro, titulado Teoría de las emociones [24], denominado también como Teoría de los afectos. Incluso, nueve ańos antes, dedicó los capítulos $5,6,7,13,16,17$ y 19 de un manual para profesores de la enseñanza media, al estudio de las emociones, los instintos, la atención y la orientación para favorecer el proceso de enseñanza-aprendizaje en los niños y adolescentes, así como el estudio de la educación estética, el talento, la creatividad y la labor del propio profesor. Ese libro apareció en español por primera vez varias décadas después de su versión original en ruso: Psicología pedagógica. Un curso breve [25].

En ambos textos, están las ideas esenciales para comprender el carácter complejo (individual y social) de las emociones, instintos humanos, intereses, motivaciones, atención, orientación y de los demás procesos vinculados al desarrollo de la motivación del aprendizaje en los estudiantes, pues entre los grandes méritos de Vigotski está el hecho de superar las limitaciones de las concepciones de sus contemporáneos sobre tales procesos de la subjetividad humana. Por todo ello, el objetivo general del presente artículo consiste en revelar la vigencia de la metodología vigotskiana de la motivación del aprendizaje de los estudiantes.

\section{DESARROLLO}

\section{ANTECEDENTES DE LOS ESTUDIOS SOBRE LA MOTIVACIÓN DEL APRENDIZAJE}

Desde las dos últimas décadas del pasado siglo, siguiendo estas ideas esenciales de la concepción histórico-cultural de la personalidad, se desarrollaron algunos trabajos que sistematizaron los fundamentos teóricos de la motivación del aprendizaje de los estudiantes mediante una serie de ideas, nociones y categorías esenciales, tales como necesidad, interés, motivo, orientación, motivación intrinseca y extrínseca [26], [27]. También, se escribieron algunos textos que profundizan en el estudio la activación de la enseñanza tanto mediante las técnicas participativas, actividad lúdica, juego, creatividad, etc. [28], [29], así como en su relación con otras configuraciones psicológicas complejas de la personalidad, tales como los sentimientos, las emociones [30], los afectos [31] y los estados de ánimo [32], procesos todos muy complejos e importantes para poder orientar [33] y elevar el nivel de motivación de los estudiantes en el desarrollo de su aprendizaje significativo [34].

Sin embargo, es preciso hacer un especial análisis de uno de los antecedentes investigativos más interesantes de este tema: la tesis de maestría desarrollada por la profesora colombiana Marleny Largo ${ }^{5}$ en la cual, desde la perspectiva histórico-cultural, la autora sistematiza un conjunto de ideas y categorías principales para contribuir al desarrollo de la motivación del aprendizaje de los estudiantes en las

5 La profesora colombiana Marleny Largo desarrolló su investigación sobre la motivación del aprendizaje de los estudiantes en las clases de educación física, en la Escuela San Pedro Claver del municipio de Villamaría, Caldas, la cual fue defendida en el Programa de Maestría en Educación del Instituto Pedagógico Latinoamericano y Caribeño de la Habana [27]. 
clases de educación física, mediante la utilización de las actividades lúdicas o el juego como vía para su formación integral [27]. En su investigación, la profesora Largo argumenta la importancia del juego como un elemento motivacional clave en la clase de Educación Física, así como enfatiza sus potencialidades para el proceso de aprendizaje en otras asignaturas. Por ello, afirma que:

La aproximación conceptual a la teoría del juego constituye el punto de partida para el análisis de lo relacionado con la motivación y dinámica de grupo. Es evidente que la actividad lúdica desempeńa papel fundamental en el desarrollo de las estructuras motivacionales; es un elemento sensibilizador por excelencia [27, p. 22].

Las bases teóricas del trabajo de esta autora no solo se sostienen en la noción de juego desde diferentes enfoques psico-pedagógicos ${ }^{6}$, sino, también, hacen especial énfasis en la perspectiva histórico-cultural, utilizando las ideas y orientaciones metodológicas de varios discípulos de L.S. Vigotski. Sin embargo, Largo no aprovecha las concepciones seminales del genio ruso ${ }^{7}$, quien sistematizó varios conceptos claves para comprender el valor motivacional del juego para el aprendizaje del estudiante, entre los cuales están: necesidad, interés, instinto, estimulación, orientación y creatividad [25], [24], [35].

Además, es muy contradictorio que la autora tampoco haya utilizado las ideas de Elkonin, una de las más prominentes continuadoras de las ideas de Vigotski sobre el valor del juego en el desarrollo de la motivación del aprendizaje [36]. No obstante, en su estudio privilegia las ideas de la psico-pedagoga rusa $R$. Jukovskaia, quien posee ideas muy interesantes para la comprensión del papel creativo del juego en la dinámica de los grupos estudiantiles. Por ello, sentencia que la autora realiza "una propuesta distinta en la que el juego está vinculado directamente al desarrollo de intereses generales de grupo que sirven para la integración social” [27, p. 26]. Asimismo, otra idea más significativa de la pedagoga rusa que Largo destaca es su comprensión del juego como "una actividad creadora que desarrolla la memoria, la imaginación y los intereses en el proceso de la enseńanza y el trabajo” [37, p. 1].

A su vez, ambas autoras reconocen que pensadores rusos como Plejanov, Makarenko, Gorki y Krupskaia enfatizaron que el juego constituye por excelencia una actividad social imaginativa, creativa y educativa, que tiene enormes potencialidades para la formación de valores, el desarrollo de la comunicación social y el crecimiento personal en el seno del trabajo cooperativo en equipo en los colectivos estudiantiles. Sin embargo, Largo no desarrolla las ideas y nociones esenciales para comprender la motivación del aprendizaje como un proceso psico-pedagógico complejo relacionado con varias categorías psicológicas, tales como necesidad, interés, motivo, orientación, expectativa, instinto, emociones, sentimientos, causas intrínsecas y extrínsecas de la motivación $n^{8}$, entre otras.

Comprender la motivación del aprendizaje mediante todas esas categorías psico-pedagógicas, así como revelar las complejidades de la relación dialéctica entre profesor-estudiante, es la clave para encontrar nuevas fuentes de motivación del aprendizaje, entre las cuales el juego y las actividades lúdicas son muy significativas.

6 En las definiciones del concepto de juego, utilizadas en su tesis de maestría por Marleny Largo, se enfatizan aspectos neuro-fisiológicos, psico-pedagógicos y organizacionales. Entre las propuestas se destacan las de: Freud, Zulliger, Lebovici, Diatkine, Klein, Piaget, Huizinga, Hirn, Gross, Thorndike, Winnicott, entre otros [27].

7 Es evidente que la autora no tuvo la oportunidad de leer los textos recientemente aparecidos de Vigotski, en especial, el titulado: "Psicología pedagógica. Un curso breve", en el cual desarrolló su teoría del juego y el papel de las actividades lúdicas en el desarrollo del aprendizaje de los jóvenes [25].

8 Varios autores enfatizan la necesidad de articular dialécticamente los aspectos intrínsecos y extrínsecos de la motivación para lograr mayor permanencia o sustentabilidad de las fuentes motivadoras del aprendizaje en jóvenes, incluso, se privilegia el fortalecimiento de la motivación intrínseca como vía para evitar los efectos efímeros y nocivos de los incentivos y recompensas como palancas de la motivación del aprendizaje [29], [26], [78], [83], [71], [27], [58], [79], [68], [65], [70], [72]. 
Por ello, Largo sugiere que los profesores deben incitar, promover y observar con detenimiento las actividades lúdicas de sus estudiantes con el fin de generar nuevas situaciones que los jóvenes puedan analizar, desarrollar su capacidad de adaptación, imaginación y creatividad, para que, en el trabajo colectivo mediante el juego de roles y funciones, puedan encontrar las soluciones más acertadas a los diferentes y complejos problemas que deben afrontar en la vida cotidiana.

De hecho, el juego y todas las formas creativas de la actividad lúdica se convierten no solo en agentes catalizadores de la motivación del aprendizaje, sino también en laboratorios virtuales que permiten realizar simulaciones de realidad cotidiana de los disímiles contextos sociales en los cuales transcurre la vida de los jóvenes, situaciones similares a las que se producen en el hogar, la escuela, el contexto laboral, etc. Por tanto, la utilización del juego combinado con el deporte, la educación física y las artes constituyen ensayos ideales para la formación de valores de socialización, comunicación y cooperación creativa entre los estudiantes, a la vez, que se convierten en actividades placenteras y productivas en los planos organizacional, ético, estético y educativo [27].

En la educación, como complejo fenómeno social, confluyen diversas disciplinas científicas: $n a-$ turales, tecnológicas, sociales y humanísticas, las cuales constituyen una vastísima área de integración de conocimientos, y, como se sabe, "un área del conocimiento, además de considerar las tradicionales formas disciplinarias de organización del conocimiento, puede incorporar enfoques multidisciplinarios, interdisciplinarios y transdisciplinarios, brindando una perspectiva de mayor integración y generalidad a las investigaciones científicas conducentes a doctorados" [38, p. 5].

En concreto, algunos autores han tratado aspectos significativos de la superación de los profesores desde diferentes paradigmas disciplinares ${ }^{9}$, por lo que para dar solución a problemas complejos se precisa cambiar el paradigma vigente en la ciencia como vía para elevar el nivel de actualización epistemológica de los propios investigadores. Por ello, en el proceso de desarrollo de la motivación del aprendizaje se precisa revelar, ante todo, las carencias epistemológicas o desactualización científica del profesor, es decir, tanto sus insuficiencias teóricas como metodológicas, las cuales no le permiten resolver los problemas complejos del proceso de enseñanza-aprendizaje.

Además, hoy se debe comprender la necesidad de un desplazamiento epistemológico y metodológico del tradicional rol protagónico del profesor en el proceso de dirección psico-pedagógica hacia un papel más humilde, es decir, el educador debe ser un ingenioso facilitador del proceso de auto-organización y auto-aprendizaje de los estudiantes, quienes deben ser los principales protagonistas de dicho proceso. En esencia, esto significa que la dirección psico-pedagógica de la motivación del aprendizaje no se puede concebir desde la simple visión lineal de la relación causa-efecto, sino estudiar la compleja dinámica de las relaciones entre sus sub-sistemas, componentes y elementos [39]. En concreto, en el complejo tema relativo al proceso de motivación del aprendizaje de los estudiantes es preciso retomar las fructíferas ideas de la tradición histórico-cultural muy poco difundidas en América Latina.

\section{LA CONCEPCIÓN DE L.S. VIGOTSKI SOBRE EL APRENDIZAJE CREATIVO CON LA AYUDA DEL MAESTRO}

En la historia de la psico-pedagogía, las concepciones de L.S. Vigotski son radicalmente revolucionarias y constituyen hoy una fuente inagotable de sabiduría para poder comprender los complejos procesos de la enseñanza y el aprendizaje, en especial, en el ámbito de la formación de la personalidad de los

9 Paradigma o matriz disciplinaria. Fue el historiador de la ciencia estadounidense Thomas Kubn (1922-1996), quien introdujo en 1962 esta noción en la academia; en esencia, significa la concepción que se puede asumir, cuando se considera el entramado social complejo, compuesto por las teorías, las creencias, técnicas, formas de hacer y valores [69, pp. 79-99], [73, pp. 82, 154-155]. 
estudiantes. En el caso del objeto de estudio que aquí se desarrolla, en lo relativo a la motivación del aprendizaje de los estudiantes, son de vital importancia las siguientes recomendaciones del genio ruso:

La investigación científica empieza por reconocer que no sólo se desarrollan los hábitos y las funciones psicológicas del niño (atención, memoria, pensamiento, etc.), sino que el desarrollo psíquico se basa ante todo en la evolución de la conducta y de los intereses del niño, en los cambios que se producen en la estructura de la orientación de su comportamiento [40, p. 2].

Desde esta perspectiva, es preciso reconocer una serie de nociones complejas que utiliza Vigotski para poder estudiar la activación del interés y la orientación de la conducta de los niños y jóvenes para estimular el aprendizaje. En verdad, Vigotski no utiliza la expresión actual de “motivación del aprendizaje”; sin embargo, al presuponer la naturaleza compleja del propio desarrollo de ese proceso, se sirve de todo un arsenal de términos estrechamente imbricados, tales como instinto humano, afectos, emociones, conducta humana, interés, orientación, imaginación y creatividad. Estas nociones y conceptos aparecen en su casi desconocido manual titulado Psicología Pedagógica. Un curso breve.

Es preciso subrayar que, entre todos esos conceptos, un especial significado para el estudio de la motivación del aprendizaje lo tiene su noción de instinto. En esencia, Vigotski asume que el instinto es un reflejo complejo o una cadena de reflejos que, como unión de varios reflejos simples y como resultado de la incidencia de estímulos externos, puede generar "una serie compleja de acciones y actos, vinculados entre sí de manera que cada acción provocará automáticamente la siguiente” [25, pp. 67-68].

En el orden fisiológico, Vigotski presenta como ejemplos de instintos los procesos de alimentación, succión y deglución, entre otros. Pero lo novedoso está en que compara, desde un enfoque sistémico, el instinto con el reflejo, perspectiva esta que le permite revelar la naturaleza humana y compleja del instinto, porque dice que "el instinto se encuentra en una vinculación mucho menos limitada y precisa que el reflejo con los elementos del medio circundante. El reflejo es un vínculo unívoco, rigurosamente definido y determinado. Por el contrario, el instinto es mucho menos determinado y más libre" [25, p. 68]. Al respecto, cuando distingue las nociones de instinto y reflejo, incluso en el plano del reino animal, pone el ejemplo de la ardilla en cautiverio, criatura en la que no deja de manifestarse el instinto de recolección y conservación en el otoño, por lo que se demuestra así el carácter flexible, plástico y complejo del instinto al relacionarse con el ambiente, a diferencia del carácter inmediato y simple del reflejo. A su vez, Vigotski reitera y enfatiza el carácter dinámico-complejo del instinto respecto al reflejo, cuando señala que

El sistema de movimientos que constituyen un reflejo está rigurosamente determinado y dado de antemano en forma totalmente precisa. Por el contrario, los movimientos instintivos nunca pueden ser predichos ni calculados de antemano por completo, nunca se presentan como un estereotipo exacto y varían de una a otra vez..., reside en la mayor complejidad de los movimiento producidos [25, p. 68].

En consecuencia, el instinto es una forma peculiar de la conducta hereditaria, que se expresa como reacción impredecible y libre de la conducta de todo el organismo, fenómeno que genera incertidumbre ${ }^{10}$. Por tanto, es una propiedad emergente del funcionamiento de todo sistema complejo. Por supuesto que Vigotski no usa estos términos, pero subyace su significado en su concepción sistémica del proceso complejo del instinto como "reacción de la conducta de todo el organismo" [25, p. 69]. Asimismo, para fundamentar el carácter complejo de los instintos, Vigotski asume un enfoque dialéctico, pues

10 Es muy importante profundizar en el origen y desarrollo de la noción de incertidumbre, para poder revelar la naturaleza compleja de los fenómenos y del propio pensamiento humano. La incertidumbre es inherente a los procesos educativos complejos como lo es el proceso de motivación del aprendizaje. 
combina, tanto la teoría evolucionista de Darwin (gradualidad en los cambios adaptativos) como las concepciones más radicales de Hugo Marie de Vries y Thomas Hunt Morgan, quienes subrayan el carácter no solo continuo, sino brusco y radical de los cambios cualitativos y mutaciones en los seres vivos. A este enfoque se le ha denominado Teoría de las mutaciones.

Aquí valdría hacer un paréntesis para profundizar en una reflexión sobre la visión psicoanalítica de la naturaleza de los instintos humanos, que inicia Sigmund Freud en su texto de 1915, "Las pulsiones y sus destinos", que luego fue enriquecida por su discípulo Cornelius Castoriadis en su artículo titulado "Pasión y conocimiento. El amor por la verdad", en el que define al instinto humano, utilizando el término acuñado por Freud de pulsión, al que le atribuye los siguientes rasgos distintivos respecto al instinto animal:

1) Carácter variable de la representación humana.

2) Carácter libre, suelto o enloquecido de la representación.

3) El placer de la representación impera sobre la representación del órgano.

4) La sublimación como conjugación del sentido personal y significación social de la actividad humana.

5) El deseo de dominio (objetivo consciente) de la realidad y de su propio cuerpo por el hombre (Freud en sus Tres ensayos).

De ello resulta, que:

La ruptura con la animalidad está condicionada por el surgimiento de la imaginación radical de la psiquis singular y del imaginario social como fuente de las instituciones, vale decir de los objetos y actividades que pueden alimentar la sublimación. Ese surgimiento destruye la regulación «instintiva» de lo animal, le agrega al placer de órgano placer de representación, hace brotar la exigencia del sentido y la significación y le responde con la creación, a nivel colectivo, de las significaciones sociales imaginarias que dan cuenta de todo lo que pueda en cada caso presentársele a la sociedad considerada [41, p. 5].

Estas reflexiones, de orientación vigotskiana y psico-analítica, tienen un especial valor para el desarrollo de la motivación del aprendizaje de los estudiantes, pues exigen al profesor tomar seriamente en consideración lo positivo de los instintos variables, flexibles y libres de sus estudiantes, en concreto, el placer de la representación del estudiante (dimensión lúdica de la actividad), lo cual constituye el detonante que el profesor necesita desarrollar para elevar el interés y la motivación de sus discípulos por el aprendizaje. Es decir, el arte del profesor de identificar ese placer de la representación del estudiante es la clave para potenciar la motivación y la creatividad, pues, mediante la facilitación de esas condiciones de placer en el quehacer cotidiano del estudiante, permite romper la rutina y el tedio y lograr la sinergia indispensable entre el significado social del aprendizaje y el sentido personal que tiene esa actividad para el estudiante.

Por último, el deseo de dominio del estudiante sobre el contenido y sobre el proceso mismo del aprendizaje también refuerza y hace más duradera tanto el interés como la motivación por el desarrollo creativo de esa actividad placentera. Ahora bien, Vigotski perfecciona su metodología psico-pedagógica, cuando determina, desde su visión sistémica, cinco factores del instinto humano:

1) Dotación biológica heredada.

2) Experiencia personal, que desarrolla su dotación genética hereditaria gracias a su relación con el entorno.

3) Experiencia que poseen los colectivos humanos. 
4) Herencia histórico-cultural de las nuevas formas de adaptación de los humanos: trabajo, herramientas, lenguaje, filosofía, ciencia, tecnología, arte, religión, etc., es decir, que en el instinto está codificado o subyace la herencia cultural social acumulada en cada individuo, en los grupos sociales y en las civilizaciones humanas.

5) Duplicación de la experiencia como conciencia humana:

a) planifica, prevé o anticipa,

b) orienta su actividad hacia un objetivo [25, pp. 87-90].

Como cierre de su concepción sobre el carácter social del instinto humano, Vigotski se detiene en la explicación del último de estos cinco factores, que diferencia de manera radical el instinto humano del animal, enfatizando la naturaleza social de las funciones de la conciencia humana, que permite al ser humano desarrollar de manera exponencial su capacidad de adaptación y transformación de la realidad. Para semejante argumentación, Vigotski hace referencia al famoso pasaje de Marx en El capital sobre la diferencia entre el hombre y las abejas, así como resume su concepción, sentenciando que:

la conciencia debe entenderse como una de las formas más complejas de organización de nuestro comportamiento, en particular — como lo señala Marx — como cierta duplicación de la experiencia que permite prever los resultados del trabajo y orientar las propias reacciones hacia ese resultado [25, p. 89].

Luego, Vigotski le dedica todo el epígrafe 5 al estudio de ese complejo proceso que es el instinto, titulado "Los instintos como objeto, mecanismo y medios". El genio ruso comenzó el análisis por el esclarecimiento del especial valor del desarrollo y orientación de los instintos como premisa para el fomento, por los maestros, del interés de los jóvenes por el estudio y las actividades que propician la creatividad. En concreto, aconseja que:

En la pedagogía de los instintos se debe promover otro principio y no la superación de los instintos, sino su máxima utilización en el proceso educativo. Desde este punto de vista, cabe hablar de construir cada vez con mayor decisión los sistemas de educación tomando como base las tendencias instintivas del niño. A la vez, tienen que ser reelaboradas formas de la actividad instintiva que ayuden a orientarlo por el camino de un desarrollo educativo útil al máximo [25, p. 152].

De hecho, desde esta visión vigotskiana, se evidencia la urgencia del sistemático estudio de diagnóstico (identificación y caracterización) de los instintos esenciales de los estudiantes, por los profesores, quienes, desde una perspectiva más integradora, deben establecer las estrategias de desarrollo de la motivación del aprendizaje. En síntesis, de lo que se trata no es de reprimir los instintos de los chicos sino potenciar y reorientar sus energías hacia la metacognición de los procesos de aprendizaje y fomentar, con ello, el pensamiento creativo en las actividades que se realizan dentro y fuera de la escuela.

A continuación, propone ejemplos concretos de la reorientación o educación de los instintos para el desarrollo del interés del estudiante y de su actividad creatividad (como forma superior humana de actividad) en los coleccionistas de sellos o filatelistas, quienes mediante el placer que genera ese peculiar hobby potencian su interés por el aprendizaje. También menciona a los ajedrecistas, quienes mediante ese juego-ciencia desarrollan gran pasión por la mejora del pensamiento lógico y la estrategia. En ese sentido, sentenció que "el principio general puede ser formulado así: la regla pedagógica básica de la educación de los instintos demanda no su mera anulación sino su utilización, su traslación a tipos más elevados de actividad” [25, p. 153].

Estas ideas de Vigotski, resumidas en su clasificación de los factores del instinto humano, constituyen la base epistemológica de la comprensión de la conciencia, de la motivación del aprendizaje y de la creatividad de los jóvenes. Luego, el genio ruso enriquece estos fundamentos en lo relativo al papel 
de la naturaleza social compleja de la esfera emocional humana (instintos, emociones, pasiones, afectos, motivaciones, etc.), concepción muy esencial para el desarrollo de la motivación del aprendizaje [35], [25, pp. 150-190], [24]. En estos textos, también, profundizó su enfoque dialéctico y sistémico, desarrollando sus ideas sobre el pensamiento creativo, en especial, en la labor del maestro como vía para el fomento de la motivación del aprendizaje de los estudiantes.

Así, también, en su obra titulada Imaginación y creación en la edad infantil, Vigotski amplifica su arsenal de nociones y conceptos, así como sistematiza las ideas más generales de su naciente epistemología y metodología sobre la creatividad, la cual es de vital importancia para que el profesor desarrolle la motivación de sus estudiantes por el aprendizaje [42]:

Cinco leyes, formas o expresiones de la creatividad (relación imaginación-realidad):

1) Las estructuras de la imaginación son tomadas de la experiencia de la realidad, acumulada por el hombre (Primera ley: la fuente de la creatividad está en la experiencia vivida):

- La fase de maduración e incubación de lo creado suele ser larga, pero su concreción o terminación puede ser repentina. Ejemplos históricos: Newton, Hamilton, Darwin y su inspiración en Maltus, etc.

2) La relación entre los productos terminados de la imaginación o fantasía de la experiencia ajena o social y los procesos complejos de la realidad: Ejemplos históricos: narraciones sobre Revolución francesa o desiertos de África (Segunda ley: el fundamento colectivo y social de la creatividad)

3) Relación emocional, afectiva, pasional o anímica con la realidad que modifica tanto la motivación por la actividad como el proceso creativo, genera impresiones internas y transforma la percepción de la realidad. Por un tono o estado emocional común se asocian ideas e imágenes, que conllevan a una alta motivación por la novedad y la creatividad, proceso este que constituye el tipo más subjetivo e interno de la imaginación.

Ejemplos de condiciones emocionales favorables para la motivación para el aprendizaje creativo: en el sueño, juego, recreación, o cualquier actividad lúdica, estado de vigilia, euforia, pasión o placer (hipnosis, catarsis, etc.) Según el genio ruso, en tales condiciones de placer hay mayor libertad y azar en las asociaciones de ideas e imágenes (a diferencia de las condiciones de rutina y lógica habitual), de manera que se constituyen en las condiciones ideales para el desarrollo de la motivación para el aprendizaje, así como para la imaginación y la creatividad.

Para Vigotski, esta constituye la Tercera ley: el carácter emocional real de la imaginación) Los efectos de la relación inversa de la imaginación hacia los instintos, emociones, pasiones y sentimientos, como expresiones exageradas o fantasiosas de la esfera emocional o afectiva (motivación positiva o negativa).

- Ejemplos positivos: la euforia del niño al suponer la presencia del padre por algún indicio asociado, o el placer experimentado por el espectador ante las obras de arte, teatro, literatura, etc.

- Ejemplos negativos: temor del niño en la habitación oscura por el saco colgado, el sufrimiento experimentado por el espectador ante las obras de arte, teatro, literatura, etc.

4) Lo creado constituyen estructuras sustancialmente nuevas: esta ley es una derivación de la anterior, pues toma independencia, gracias a que la imaginación y la fantasía se instituyen o convierten (con vida propia) en innovaciones tecnológicas, sociales y obras de arte, que generan nuevas creaciones personales, colectivas y sociales. (Cuarta ley: la objetivación y autonomía de lo creado) 
Ejemplos: imágenes "cristalizadas" que cobran vida propia, tales como: una obra de teatro, una novela, la poesía, etc.; las cuales "son re-creadas" por sus espectadores/co-creadores de la obra:

- La novela de Alexander Pushkin: "La hija del capitán”, en la que se narra la fábula del "Águila y el Cuervo", en la que se muestra la confrontación entre la actitud rebelde del Águila (come carne fresca) y la conservadora del Cuervo (come carroña) ante la vida. Permite trasmitir de manera poética un poderoso mensaje aleccionador y educativo, expresado en la fantasía de esa fábula.

- La obra de Nicolai Vasílievich Gogol: "El Inspector”, que fue puesta en escena ante el Zar Nicolai de Rusia, ejerció una crítica demoledora a su propio Imperio y, sin embargo, el Zar no tomó ninguna represalia contra su escritor, gracias al poder persuasivo de su naturaleza artística: metafórica, figurada, jocosa, divertida, satírica, cómica, ingeniosa y creativa.

- La obra de León Tolstoi: "La guerra y la paz", la construcción del personaje de Natasha, como simbiosis de las características más distintivas de sus propios familiares: Tania su cuñada y Sonia su esposa [42, pp. 8-13].

a) Carácter condicionante o regulador del entorno sobre la dinámica del sistema. Es decir, cuanto más rico y complejo sea el entorno, tanto más creativo puede ser el sistema para poder mantener su identidad, evolucionar y desarrollarse. Por ello, Vigotski sentenció que: "en la psicología se estableció una ley según la cual la tendencia a la creación es inversamente proporcional a la simplicidad del medio" [42, p. 18] (Quinta ley).

5) Esta quinta ley, muy enfatizada por Vigotski, no la incluyó en su clasificación al inicio del texto, pero la dejó para la parte final, dado el valor esencialmente epistemológico y metodológico que tiene para el desarrollo de la motivación y de la creatividad. Su fundamentación fue ampliada cuando describió los denominados "factores psicológicos" de la imaginación creativa, especialmente, el factor número, es decir, la exageración o aumento de las cosas para enfatizar lo diferente y nuevo con respecto a los demás.

Condicionantes sociales del entorno sobre el sistema, donde la actividad creativa puede ser bien potenciada o bien afectada por el medio [42, pp. 16-18].

Ahora bien, este controvertido tema: del carácter condicionante del entorno sobre la evolución del sistema puede tener otras lecturas, entre ellas, el asunto relacionado con las potencialidades creativas del sistema, que, en casos excepcionales, aparecen bajo las terribles condiciones de hostilidad del entorno hacia el sistema, tales creaciones pueden ser: cientificas, tecnológicas y artísticas, que han nacido, por ejemplo, bajo la enorme presión del hambre, de las privaciones de libertad, crisis económicas, o en condiciones de calamidades y catástrofes, etc. La historia está repleta de ejemplos que ilustran la certeza de esta concepción dialéctico-compleja de la relación entre sistema y entorno, en especial, del papel decisivo jugado por la creatividad en condiciones extremas en la historia de las civilizaciones.

En el caso del desarrollo de la motivación del aprendizaje de los jóvenes de parte del profesor, juega un papel primordial su capacidad y actitud para romper la rutina y no dejarse atrapar por la monotonía y la inercia inherente a los procesos educacionales cotidianos. Tanto el escepticismo organizado como la inconformidad con el orden social e institucional establecidos son herramientas indispensables para que el profesor pueda emprender una labor más creativa y promueva el desarrollo de la motivación creciente del estudiante por el autoaprendizaje. Precisamente, en ello radica la importancia teórico-metodológica de la concepción vigotskiana de la activación del proceso de enseñanzaaprendizaje y de la creatividad del profesor y de los estudiantes. 


\section{LA METODOLOGÍA DE L. S. VIGOTSKI PARA EL DESARROLLO DEL PENSAMIENTO CREATIVO Y SU VALOR PARA LA MOTIVACIÓN DEL APRENDIZAJE DEL ESTUDIANTE}

Vigotski no se queda solo en la fundamentación epistemológica de su teoría sobre la creatividad, sino que desarrolla también una peculiar metodología, la cual comienza a caracterizar enfatizando la naturaleza compleja del proceso de la imaginación creadora:

Como puede apreciarse a partir de todo lo expresado anteriormente, la imaginación es un proceso muy complejo por su composición; precisamente esta complejidad origina la dificultad principal para el estudio del proceso de creación y conduce con frecuencia a falsas representaciones con respecto a la propia naturaleza de este proceso y su carácter como algo extraordinario y completamente excepcional [42, p. 15].

El complejísimo proceso de la imaginación creadora es caracterizado por Vigotski mediante las denominadas fases o etapas del pensamiento creativo:

1) Acumulación de las experiencias y los conocimientos por el niño del "material" con el cual estructurará su fantasía (percepciones exteriores e interiores).

2) Proceso de transformación del material:

a) Disociación de las impresiones percibidas (aumento, disminución, sobrevaloración o exageración)

b) Asociación de las impresiones percibidas o de los elementos disociados o transformados.

3) Combinación de las diferentes impresiones (ideas o imágenes) y reorganización o construcción de un sistema complejo nuevo, inventado, creado o reelaborado.

4) Materialización, objetivación o "cristalización” de la idealización (imaginación, creación o fantasía) en imágenes o cosas exteriores.

El verdadero valor de esta metodología propuesta por Vigotski radica en comprender el carácter didáctico de su explicación de los dos momentos opuestos, pero complementarios a la vez, que constituyen el proceso complejo de: disociación y asociación de las ideas y las imágenes en las representaciones humanas. Con relación a este complejo proceso en general y a la disociación en particular, Vigotski sentencia que:

Toda impresión representa un todo complejo compuesto de un conjunto de diferentes partes, la disociación consiste en que este todo complejo podríamos decir que se divide en partes y cada una de ellas se destaca principalmente en comparación con las demás, unas se conservan y otras se olvidan; la disociación constituye la condición necesaria para la actividad futura de la fantasía [42, p. 15].

Además, la disociación ha sido un proceso extremadamente importante en el desarrollo intelectual del ser humano en la historia, ya que "forma la base del pensamiento abstracto y de la formación de los conceptos" [42, p. 15]. Ahora bien, aquí se debe hacer un especial paréntesis para explicar el valor didáctico que tienen para el desarrollo de la creatividad las asociaciones de ideas e imágenes. En concreto, Vigotski nos enseña que las asociaciones más fantásticas, simbólicas, metafóricas y aberradas ${ }^{11}$

11 Para profundizar en el estudio del valor teórico y metodológico de la imaginación, la fantasía, las metáforas, el simbolismo y otros atributos del pensamiento intuitivo y, en especial, en el estudio y comprensión de la evolución de la vida, ver los trabajos de: [42], [45], [43], [61]. 
pueden multiplicar hasta el infinito la creatividad del pensamiento humano en todos los dominios: filosofía, ciencia, artes, etc.

Actualmente, algunos investigadores continúan enfatizando la necesidad de desarrollar en la ciencia el uso de la imaginación, la fantasía y otros atributos del pensamiento intuitivo, muchas veces sin saber ellos mismos que ya Ribot y Vigotski lo habían fundamentado en las primeras décadas del siglo XX. Por ejemplo, como afirma James Lovelock, es preciso comprender que la imaginación y las metáforas son recursos indispensables para el desarrollo de la creatividad científica. Al respecto, al referirse a la insistencia de los críticos de su teoría Gaia, Lovelock sentenció en su libro que la mayoría de los científicos

tienden a descartar nuestras ideas por "fantásticas y metafóricas". Parecen ver la metáfora como algo peyorativo, inexacto y, por tanto, nada científico. Sin embargo, la ciencia verdadera está plegada de metáforas y crece a partir de modelos imaginarios, puliéndose después por ajustes que acoplan esos modelos a la realidad [43, p. 11].

Con relación al papel de la imaginación y la fantasía en la investigación científica, Vigotski nos regaló una anticipatoria visión crítica de lo que hoy no se hace, cuando expresó que:

A veces por imaginación o fantasía no se tiene en cuenta todo lo que se sobreentiende por esas palabras en la ciencia. En la vida cotidiana se llama imaginación o fantasía a todo lo que no es real, a lo que no concuerda con la realidad y lo que, de esta forma, no puede tener ningún significado práctico serio. En efecto, la imaginación como fundamento de toda actividad creadora se manifiesta decididamente en todos los aspectos de la vida cultural haciendo posible la creación artística, científica y técnica [42, p. 4].

Lamentablemente, las actuales concepciones reduccionistas del positivismo, que todavía se manifiestan entre muchos de los profesores e investigadores, incluso entre la mayoría de los "flamantes" miembros de tribunales doctorales en todo el mundo, no admiten la presencia del lenguaje coloquial, imaginativo, metafórico, lúdico y creativo, propio de las humanidades y de las artes, en los artículos, libros y tesis científicas. Por eso, para quienes están todavía aferrados al metodologismo neopositivista esquemático y pedante típico del tradicional discurso científico, van las siguientes visionarias reflexiones, citadas por Vigotski, de Ribot sobre el valor de la imaginación y la fantasía en la historia de la tecnología:

Toda invención -según Ribot- grande o pequeña, antes de cobrar forma ha sido producto de la imaginación, una idea formada y trazada en la mente mediante nuevas combinaciones y correlaciones... La gran mayoría de las invenciones ha sido creada por personas desconocidas; solamente se conocen algunos nombres de grandes inventores. La imaginación sigue siendo la misma, independientemente de la forma en que se manifieste: en una personalidad o en un colectivo [42, p. 4].

Para completar su metodología sobre el pensamiento creativo, Vigotski recurre al enfoque sistémico en el análisis psicológico de la creatividad, pues enfatiza el papel de las necesidades y las aspiraciones del ser humano, en este caso, del profesor y del estudiante, para transformar el entorno, dado su inconformidad con el tradicional mimetismo adaptativo. Por tanto, según su anticipatoria concepción, para poder evolucionar y desarrollarse el educando debe transformar su entorno y a sí mismo, creatividad indispensable para que pueda garantizar lo que hoy se denomina como su robustez adaptativa y sustentabilidad. En síntesis, Vigotski resume el conjunto de "factores psicológicos" de la imaginación creadora en:

1) Experiencias del estudiante

2) Necesidades 
3) Intereses

4) Capacidad combinatoria de imágenes e ideas

5) Ejercitación sistemática de esa actividad imaginativa, mediante la exageración numérica como vía para potenciar la creatividad

6) Materialización de los productos de la imaginación

7) Influencias de las habilidades técnicas y tradiciones culturales del estudiante

8) Condicionantes sociales del entorno sobre el sistema psicológico del estudiante, donde la actividad creativa puede ser bien potenciada o bien afectada por el medio [42, pp. 15-16].

Sobre estos condicionantes sociales de la imaginación creadora, Vigotski hace una argumentación histórico-cultural que se resumen en la siguiente sentencia:

Todo inventor, incluso el genio, es siempre un fruto de su tiempo y de su medio, su creación parte de las necesidades que están creadas antes de él y se apoya en las posibilidades que además existen fuera de él; por eso observamos un estricto orden en el desarrollo histórico de la técnica y la ciencia. Ninguna invención o descubrimiento científico aparece antes de que se creen las condiciones materiales y psicológicas necesarias para su surgimiento [42, pp. 16-17].

Además, Vigotski profundiza su metodología sobre el pensamiento creativo en el capítulo 4, referido a "La imaginación creadora en el niño y en el adolescente", en el que realiza un análisis psico-pedagógico de las particularidades de la imaginación y la creatividad en esas edades, comparándolas con las del adulto, quien debe tratar siempre de mantener viva la capacidad de jugar, divertirse y fantasear como premisas esenciales para la actividad y el pensamiento creativos.

También, hace énfasis en la argumentación del carácter más complejo de los procesos creativos en la adultez, en la cual tiende a desaparecer el disfrute del juego y de otras actividades lúdicas, por lo que sugiere aprender a rescatar y caracterizar las particularidades de la actividad imaginativa de los jóvenes, utilizando los conceptos de imaginación plástica y emocional (externa e interna). Para la labor de los profesores, es de vital importancia atender esta recomendación de Vigotski, pues cada profesor debe ponerse en los zapatos de los estudiantes y, en alguna medida, regresar a los placeres de la niñez y la adolescencia como vía para facilitar el aprendizaje de estos.

De manera que para Vigotski, las motivaciones, las emociones y los estados anímicos del niño, adolescente o del joven, pero, en especial, del profesor como científico, constituyen premisas psicológicas indispensables y fuentes inagotables para el desarrollo de la motivación del aprendizaje y de la imaginación y la creatividad. En esto radica lo más revolucionario de la metodología de la creatividad de Vigotski.

Por tanto, para el fomento del pensamiento creativo son muy importantes, tanto la actividad lúdica, el juego, como otras actividades placenteras que los profesores y estudiantes puedan realizar, porque bajo las condiciones de alta motivación y concentración (placer, sugestión, hipnosis y catarsis) el ser humano crea cosas maravillosas. Precisamente, bajo esas condiciones favorables como el juego es que se disparan y potencian la intuición, la fantasía, la imaginación y demás atributos del pensamiento creativo. Por ejemplo, según nos enseña Vigotski, "el juego del niño no es el recuerdo simple de lo vivido, sino la transformación creadora de las impresiones vividas, la combinación y organización de estas impresiones para la formación de una nueva realidad que responda a las exigencias e inclinaciones del propio niño" [42, p. 5]. Sin embargo, esta revolucionaria visión de Vigotski sobre la creatividad contrasta mucho con lo que está sucediendo hoy en la actividad docente, en especial, en el ámbito de la educación, en la que impera la visión reduccionista del positivismo que proscribe el juego y demás actividades lúdicas en el desarrollo del aprendizaje. 
Por el contrario, hoy, en las condiciones peculiares y enajenante de la globalización neoliberal, se debe reconocer más que nunca el valor y las potencialidades del juego y de las demás actividades lúdicas en el proceso de activación de la enseñanza y de la motivación del auto-aprendizaje creativo de los estudiantes. Es preciso eliminar de una vez el mito de las dos culturas ${ }^{12}$, es decir, potenciar la creatividad y fertilización mutua de las ciencias naturales, técnicas y sociales, así como lo reveló el apóstol cubano José Martí en su elocuente y hermosa crónica sobre la complementariedad de las creaciones de dos genios de la ciencia y de la literatura: Edison y Emerson. Un siglo después, en este mismo sentido, Marcelo Pakman al valorar el pensamiento creativo de Edgar Morin, dice que le caracteriza:

un estilo que une lo literario al discurso tradicionalmente considerado más científico (objetivista) es expresión de esa unión fecunda de lo personal y social, de lo aleatorio, con lo racional y reflexivo, con el intento de ordenar y estructurar, para cuestionar nuevamente en un proceso sin fin [44, p. 13].

Este proceder transdisciplinario del pensamiento de Morin es de cardinal importancia para lograr la creatividad no solo en los ámbitos filosófico y científico, sino también en el peculiar contexto de la educación de jóvenes. Además, esta idea es una clara expresión de la sugerencia de Gregory Bateson de que el pensamiento, en sus dimensiones racional e intuitiva (instintiva, lúdica e imaginativa), debe ser fomentado por los profesores en sus estudiantes, tratando que ambos estilos se fertilicen mutuamente para lograr la ańorada creatividad [45, pp. 65-75].

Además, Vigotski menciona a varios pensadores y científicos que enfatizaron el valor de la imaginación en el desarrollo del arte, la cultura y las ciencias, además de dedicarse a fundamentar el papel del medio social para el desarrollo del talento y la genialidad. Por ello, hace referencia a varios nińos prodigios en la historia, tales como Mozart, Mendelson, Haynd, Haendel, Weber, Schubert, Cherubini, Giotto, Van Dyck, Rafael, Miguel Ángel, Durero, Bernini, Rubens, Jordan, etc. [42, pp. 20-21]. Luego, el genio ruso en el capítulo 5, "El martirio de la creación", hace un análisis de las implicaciones metodológicas que tiene para el desarrollo de la imaginación, la cuarta y última fase del proceso creativo: la materialización de la imaginación, en la que se cierra el círculo de la creatividad: de la realidad a la imaginación y de esta de vuelta a la realidad (bucle recursivo, según la terminología actual de Edgar Morin).

Para lograr fundamentar mejor e ilustrar este complejo proceso, Vigotski se apoya en las contribuciones de Dostoievski, Lérmontov, Gornfeld y Lunacharski, quienes de manera muy ingeniosa hacen referencia al denominado "martirio de la creación y de la palabra" en la complicada labor del escritor o del poeta, relativo al difícil y desgarrador parto creativo del autor en la literatura. Dado su enorme valor pedagógico, Vigotski transcribe un párrafo completo de Ribot, precisamente, sobre la similitud entre imaginación y voluntad (teoría y práctica), así como sobre la diferencia entre la imaginación creativa en función de la solución de un problema práctico y las elucubraciones teorizantes de un sońador o charlatán:

La imaginación en la esfera intelectual corresponde a la voluntad en la esfera de la acción (...). El hombre siempre quiere algo, ya sea importante o no, inventa siempre con un objetivo conocido (...) La voluntad en su forma normal y completa, termina con la acción, pero en las personas indecisas y faltas de voluntad las vacilaciones no terminan nunca o la decisión queda sin efectuarse, incapaz de realizarse o confirmarse en la práctica. La imaginación creadora en su forma completa trata exteriormente de

12 El mito de las dos culturas se refiere a la oposición burocrática o incomunicación entre las ciencias naturales y técnicas por un lado y las ciencias sociales y las humanidades por el otro [62], [59], [69], [77, p. 75] Sin embargo, un siglo antes de los autores mencionados, un indiscutible precursor de la crítica a semejante mito fue José Martí el apóstol cubano, quien escribió una hermosa crónica sobre la complementariedad de las obras de dos grandes genios norteamericanos: Edison y Emerson [76], [75, p. 283] 
confirmarse con algo que existe no solo para el propio creador, sino también para todos los demás. [46], citado por [42, p. 23].

Es impresionante el valor didáctico y ético de estas ideas de Ribot, citadas por Vigotski, especialmente, para el ejercicio de la dura labor de investigación diaria que debe realizar el maestro o profesor, que supone también la realización de investigaciones y documentos científico-metodológicos serios en todas sus fases: planeación, ejecución, control (diagnóstico y evaluación). También, Vigotski hace una pedagógica y clínico-profiláctica recomendación a los profesores sobre la necesidad de tener presente, diagnosticar e identificar en cada estudiante el doble carácter de la imaginación en los adolescentes: constructivo-creativa y destructivo-enajenante, pues depende mucho de la manera en que el entorno social (familiar, escolar y comunitario) propicie o entorpezca el desarrollo hacia una u otra tendencia espiritual del joven [42, p. 22].

Por otro lado, la novedad de la labor científico-metodológica del profesor depende de una enorme carga de investigación, de la minuciosa pesquisa de todo los avances, que, en el orden teórico y práctico, se han realizado sobre el tema en cuestión, en este caso de la motivación del aprendizaje de los estudiantes, es decir, es preciso, para ser realmente creativos, revelar el llamado colegio invisible ${ }^{13}$, pero más que todo exige del profesor-investigador una altísima motivación y amor por lo que hace, de manera que en cada minuto o instante de lectura, de trabajo solitario y paciente de indagación profunda en las obras que estudia, siempre encuentre placer, satisfacción y éxitos renovados.

Recuérdese que el éxito no está esperando en ningún lugar, pues como dice el poeta Machado, "Caminante, no hay camino,/ se hace camino al andar" y, parafraseando a Benedetti: "Debemos hacer exitoso cada minuto de nuestras vidas". Por tanto, para llevar a término lo que el profesor hace en su trabajo sistemático para la motivación del aprendizaje de los estudiantes, se necesita no solo mucha imaginación y pasión, sino también férrea voluntad y perseverancia.

$\mathrm{Al}$ respecto, Vigotski utiliza una premonitoria sentencia, realizada por Lunacharski (anti-positivista y de estirpe integradora por su contenido implícito), sobre el valor de la fantasía para el desarrollo de la creatividad en todos los dominios de la vida, pero que tiene un especial significado para combatir el reduccionismo, la desactualización y falta de novedad imperantes en la actual metodología de la investigación psico-pedagógica, así como sus estereotipadas y esquemáticas exigencias en la redacción de los trabajos "científicos": "El papel de la fantasía combinadora en el futuro de ningún modo será menor que en la actualidad. Es muy probable que adopte un carácter peculiar que combine elementos científicos experimentales con los vuelos más elevados de la fantasía intelectual y artística” [42, p. 25].

Así, también, para poder profundizar su teoría y su metodología sobre la creatividad, Vigotski estudió en detalles las particularidades e implicaciones futuras de la actividad creativa de los niños y de los adolescentes, en especial, sobre el dibujo y la escritura, respectivamente. Esas ideas de Vigotski tienen hoy un gran significado para la educación en general, pero, en especial, para anticipar y resolver los problemas que hoy tienen los estudiantes en cuanto a sus limitaciones en la motivación para el aprendizaje y de falta de creatividad [42, pp. 23-25].

En verdad, es preciso rescatar esta revolucionaria visión de Vigotski sobre el carácter favorecedor y potenciador de las actividades lúdicas y de los estados de placer para el desarrollo de la motivación del aprendizaje y de la creatividad en los jóvenes. Por otro lado, un especial significado para potenciar la motivación del aprendizaje de los estudiantes lo tiene la teoría de L.S. Vigotski sobre la denominada

13 En la historia esta noción de colegio invisible fue introducida por David Crane en 1972 y se refiere al paradójico aislamiento entre los investigadores de la borrosa vanguardia científica (en el frente de las investigaciones, como dice Price, o en la punta o borde delantero del conocimiento), constituida por cultores de diversas disciplinas, quienes, dispersos por todo el mundo y la mayoría de las veces sin conocerse entre sí, están trabajando en temas afines, pero desde diferentes enfoque [82], [60], [66], [69]. 
Zona de Desarrollo Próximo, la cual fue elaborada en varios trabajos suyos, entre los cuales se destacan: [47], [48]. En síntesis, se puede afirmar que:

Entre estas ideas estaban la integración de lo cognitivo y lo afectivo en formas complejas de organización de la personalidad humana, la superación de la dicotomía entre lo externo y lo interno y entre lo social y lo individual, así como el planteamiento de formas de organización complejas y procesuales de la psique, como fueron el concepto de personalidad y de funciones psíquicas superiores. También las categorías de significación y sentido de Vigotski resultaban promisorias para el desarrollo del tema de la subjetividad [49, p. 134].

Para su consecuente sistematización, es muy didáctico resumir las concepciones de Vigotski, en las siguientes ideas:

1) El desarrollo psíquico no aparece como simple adaptación mimética del ser humano al medio, sino como posesión (dominio), asimilación y transformación (el trabajo y sus instrumentos) de los valores de la cultura humana, pues posee una determinación históricocultural compleja.

2) Los procesos psíquicos están estrechamente relacionados con el desarrollo de la personalidad en cada individuo, por lo que se deben considerar las particularidades psicológicas de cada estudiante para desarrollar sus estrategias de aprendizajes.

3) El tránsito de la actividad social a la individual propicia el proceso de interiorización, de aquí el valor didáctico del trabajo del estudiante con los demás compañeros, es decir, del trabajo en equipo o colectivo [50].

4) La consideración del carácter activo de los procesos psíquicos, indica que las estrategias de aprendizaje se deben desarrollar mediante la realización de actividades y tareas constantes, superando la pasividad que impone la enseńanza memorística [48].

5) Los procesos psíquicos tienen carácter consciente, por lo que las estrategias de aprendizaje deben ser orientadas por el profesor con la participación protagónica del estudiante (liderazgo colectivo por participación distribuida de roles y funciones, de manera no directiva sino democrática) en los tres momentos esenciales del proceso de dirección: planeación, ejecución y control (diagnóstico y evaluación).

6) No solo basta con incentivar el interés del estudiante por el aprendizaje en el plano emocional, sino también orientar su actividad creativa en el plano del proceso lógico del conocimiento, para cumplir así con el principio de la unidad de lo afectivo y lo cognitivo.

7) El desarrollo mental del estudiante (adolescente y joven) se debe concebir desde dos niveles esenciales:

a) El nivel evolutivo real: que se puede determinar según los ciclos evolutivos que establecen los productos finales del desarrollo cognitivo, así como las funciones que ya van alcanzado cierto grado de maduración en cada estudiante, lo cual le proporciona la capacidad de resolver, de manera independiente, problemas concretos en el proceso de aprendizaje.

b) El nivel de desarrollo potencial: es esa tendencia a desarrollar una capacidad posterior para resolver un problema bajo la guía de un adulto, profesor o en colaboración con otro compañero más capaz.

Precisamente, el espacio o diferencia cualitativa en la resolución de problemas que media entre ambos niveles de evolución de las capacidades del estudiante, es lo que Vigotski denomina “Zona de Desarrollo Próximo”[47, p. 133], [50, pp. 22-26]. 
8) En esencia, el arte de identificar por el profesor esa zona de desarrollo del aprendizaje del estudiante es la clave para poder trabajar en la didáctica de la enseńanza de manera personalizada para contribuir a la orientación de los progresos lógicos del estudiante.

9) Es mucho más importante lograr la maduración de las funciones del pensamiento, expresadas en el proceso mismo de orientación y de desarrollo de operaciones y habilidades lógicas, que preocuparse en demasía por los resultados o el volumen de conocimientos adquiridos. Por tanto, la labor del profesor es cultivar los hábitos, las habilidades y las capacidades de auto-aprendizaje en lugar de atiborrar de conocimientos al estudiante. Esta es una premonitoria visión vigotskiana contra los vicios de la enseñanza memorística criticada en los trabajos de varios pedagogos latinoamericanos, entre los cuales destaca la obra de [51].

En consecuencia, la teoría vigotskiana de la Zona de Desarrollo Próximo tiene un enorme valor metodológico, ya que exige realizar tanto un preliminar diagnóstico de cada estudiante, así como propicia las herramientas didácticas necesarias para conducir con sabiduría el proceso de aprendizaje del estudiante. En verdad, Vigotski establece las líneas más generales para el estudio de la dinámica compleja de las relaciones psicopedagógicas de los profesores y los estudiantes; sin embargo, existe una serie de aspectos metodológicos en los cuales no pudo profundizar, así como tampoco podía prever los impactos nocivos inherentes al desarrollo de las nuevas tecnologías de las telecomunicaciones en el ámbito de la formación educativa.

\section{CONCLUSIONES}

En síntesis, en la actualidad, varios investigadores han reconocido y enfatizado la necesidad de aplicar y enriquecer las concepciones vigotskianas, tanto de la Zona de Desarrollo Próximo en general como en su metodología de la motivación del aprendizaje en particular. Asimismo, consideran que se deben desarrollar otros aspectos esenciales tales como:

a) El complejo problema del traspaso del control de la tarea del profesor al estudiante, que ha encontrado una ingeniosa alternativa en la propuesta de la idea de la participación guiada como actividad conjunta, en la cual las acciones del profesor van dirigidas y ajustadas (adaptadas a la personalidad) a la estructuración preliminar de la tarea a desarrollar por el estudiante, de manera que le sea significativa y motivante [52], [53].

b) En la actividad conjunta profesor-estudiante, en función del desarrollo del proceso de enseñanza-aprendizaje, se incorporaron dos ideas innovadoras con la definición de la situación y los estados de intersubjetividad, mediante el papel dinamizador del sentido y la implicación personal de los educandos, que, a la vez, potencian su motivación para la participación creativa en el proceso de aprendizaje [54], [55], [56].

c) Así también, en la última década del siglo pasado se sugiere la idea de que en la Zona de Desarrollo Próximo coexisten dos zonas peculiares: la Zona de Libertad de Movimiento y la Zona de Acciones Promovidas, las cuales constituyen aspectos complementarios que aparecen en el proceso de interacción entre el profesor y el estudiante. En concreto, constituyen acciones negociables y de reajustes mutuamente establecidas y colegidas con el objetivo de elevar la eficacia de las técnicas y métodos de enseñanza, mediante la aplicación del principio de reflexividad (actitud autocrítica del profesor), así como con la finalidad de que se pueda elevar más la motivación del aprendizaje de los estudiantes, mediante la 
identificación de aquellos conocimientos, habilidades y valores significativos para cada estudiante en las situaciones escolares concretas [57], [50, pp. 24-26], [58, p. 34].

En resumen, el legado psico-pedagógico de Vigotski sigue siendo un faro indispensable para la labor creativa de los maestros y profesores en función del desarrollo de la motivación del aprendizaje de sus estudiantes. No obstante, tendría mucho mayor valor didáctico si se fertiliza de manera innovadora, utilizando las recientes contribuciones de las diversas tendencias y escuelas psico-pedagógicas articuladas hoy en los denominados paradigmas emergentes.

\section{REFERENCIAS BIBLIOGRÁFICAS}

[1] Vigotski, L.S., Psicología Pedagógica. Un curso breve, Buenos Aires: Aique, 2000.

[2] MINED, La escuela como micro-universidad en la formación integral de los estudiantes de carreras pedagógicas, La Habana: Pueblo y Educación, 2003.

[3] Cardona, G., «Teorías de aprendizaje mediadas por Internet». Ponencia presentada al IV Congreso Internacional sobre sistemas de aprendizaje en línea. Noviembre 24-26, Medellín, 1999.

[4] Cabero, J., "Los recursos didácticos y las TIC» de Enseñanza, profesores y Universidad, Tarragona, Universidad de Rovira y Virgili, 2002.

[5] Álvarez, I. \& Fuentes, H., Didáctica del proceso de formación de los profesionales asistido por las tecnologías de la información y la comunicación, Santiago de Cuba: Universidad de Oriente, 2003.

[6] Colás, P. \& De Pablos, J., La formación del profesorado basada en redes de aprendizaje virtual: aplicación de la técnica $D A F O$, Sevilla: Equipo de Investigación, Evaluación y Tecnología Educativa de la Universidad de Sevilla, 2005.

[7] Ferreira, G.L., «Modelo curricular para la disciplina integradora en las carreras de perfil técnico e informático y su aplicación en la carrera Ciencia de la Computación». Tesis de Doctorado, Universidad de Las Villas "Martha Abreu”, Santa Clara, 2005.

[8] Velázquez, E., «Estrategia didáctica para estimular el aprendizaje reflexivo en los estudiantes de las carreras de ciencias naturales de los institutos superiores pedagógicos». Tesis de doctorado, Instituto Superior Pedagógico "José Martî”, Camagüey, 2006.

[9] Martínez-Álvarez, F.F. \& Cuenca, M.M., «La perspectiva transdisciplinaria y la metodología de la investigación social», de La lógica del proceso de investigación, Quito, Editorial Jurídica del Ecuador. Universidad Regional Autónoma de los Andes, 2017, pp. 37-51.

[10] Bonilla, I., «Las estrategias de aprendizaje y su relación con el rendimiento académico en alumnos de preuniversitario». Tesis de Maestría, Universidad de la Habana. Facultad de Psicología, La Habana, 2005.

[11] Añorga, J. \& et al., La Educación Avanzada y el Diseño Curricular, La Habana: CENESEDA. Instituto Superior Pedagógico "Enrique José Varona”, 1995.

[12] De Armas, N. \& et al., Los Resultados científicos: Sistema, Modelo y Estrategia, Santa Clara: Universidad Pedagógica "Félix Varela" de Villa Clara, 2005.

[13] Valle, A., Metamodelos de investigación pedagógica, La Habana: ICCP, 2007.

[14] Betancourt, J. \& Martínez-Álvarez, F., «Dimensión educativa de una estrategia de superación transdisciplinaria para la gestión de proyectos de investigación en salud», Qhalikay. Revista de Ciencias de la Salud, no. 3, pp. 133-149, 2017.

[15] Congreso de la República de Colombia, «Ley 30 de diciembre 28 de 1992. Sobre el servicio público de la Educación Superior», Editorial del Congreso de la República, Bogotá, 1992. 
[16] Maldonado, C.E. \& et. al., Visiones sobre la complejidad, Santafé de Bogotá: Ediciones El Bosque, 1999, p. 128.

[17] Moreno, J.C., «Tres teorías que dieron origen al pensamiento complejo: sistémica, cibernética e información», de Manual de iniciación pedagógica al Pensamiento Complejo, Bogotá, ICFESUNESCO, 2002a, pp. 24-.35.

[18] Velilla, M.A., Manual de iniciación pedagógica al Pensamiento Complejo, Bogotá: ICFESUNESCO, 2002, p. 254.

[19] Restrepo, B., «Investigación formativa e investigación productiva de conocimiento en la universidad», Revista Nómadas no 18, pp. 195-202, 2003 [En línea]. Disponible en: http://www.ucentral. edu.co/images/stories/iesco/revista_nomadas/18/nomadas _18_18_inv_formativa.PDF [Accedido: 2-jun-2018]

[20] Bozhovich, L.I., La personalidad y su formación en la edad infantil, Habana: Pueblo y Educación, 1985.

[21] González-Rey, F., Epistemología cualitativa y subjetividad, La Habana: Pueblo y Educación, 1997.

[22] Vigotski, L.S., Pensamiento y lenguaje, La Habana: Pueblo y Educación, 1982.

[23] Carretero, M., «La relevancia de la obra de Vigotski para la educación. Prólogo al libro de L.S. Vigotski,» de Psicología pedagógica. Curso breve, Buenos Aires, Editorial AIQUE, 2000, pp. 8-11.

[24] Vigotski, L.S., Teoría de las Emociones, Madrid: AKAL, 2004.

[25] Vigotski, L.S., Psicología Pedagógica. Un curso breve, Buenos Aires: Aique, 2000.

[26] González-Collera, L.A., «Motivación humana. Una alternativa para su estudio en jóvenes y adolescentes. Tesis de Maestría en Educación", Instituto Pedagógico Latinoamericano y Caribeño, La Habana, 1996.

[27] Largo, M., «Motivación de los estudiantes para la clase de educación física (cuando esta no es fútbol) Tesis de Maestría en Educación», Instituto Pedagógico Latinoamericano y Caribeño, La Habana, 1999.

[28] De Bono, E., El pensamiento lateral. Manual de creatividad, Barcelona: Paidós, 1980.

[29] Canfux, V.; González, O. \& et. al., Los métodos participativos: ¿una nueva concepción de la enseñan$z a$ ?, La Habana: CEPES de la Universidad de La Habana, 1995.

[30] Extremera, N. \& Fernández, P., «El papel de la inteligencia emocional en el alumnado: evidencias empíricas», Revista Electrónica de Investigación Educativa, vol. 6, no. 2, 2004.

[31] González-Rey, F., «La afectividad desde una perspectiva de la subjetividad», Psicología: Teoria e Pesquisa, 1999.

[32] Barrios, R., «Elaboración de un instrumento para evaluar estados de ánimo en deportistas de alto rendimiento». Tesis de doctorado, La Habana.: Universidad de las Ciencias de la Cultura Física y el Deporte "Manuel Fajardo", 2011.

[33] Sobrado, L. \& et. al., "Evaluación de las competencias de estudio en los alumnos de 12-14 años», Orientación y Sociedad, vol. 3, pp. 67-73, 2001.

[34] Viera, T., «El aprendizaje verbal significativo de Ausubel. Algunas consideraciones desde el enfoque histórico cultural», Revista Universidades de UDUAL. México, no. 25, 2003.

[35] Vigotski, L.S., Psicología del Arte. Tomo I, Barcelona: Barral Editores, 1972.

[36] Elkonin, D.B., Psicología del juego, La Habana: Pueblo y Educación, 1984.

[37] Jukovskaia, R.I., La educación del niño en el juego, La Habana: Pueblo y Educación, 1978.

[38] Pérez, M.T., "Cambios en el Sistema Nacional de Grados Científicos de la República de Cuba», Comisión Nacional de Grados Científicos de la República de Cuba, La Habana, 2014.

[39] Franco, R. \& Dieterich, H., «Aportes de las ciencias naturales a la posibilidad de la democracia», de Fin del Capitalismo Global. El nuevo Proyecto histórico, México, Nuestro Tiempo, 1998, pp. 81-104. 
[40] Vigotski, L.S., «Paidología del adolescente», de Obras Escogidas. Tomo IV. Psicología infantil, Moscú, Progreso, 2000.

[41] Castoriadis, C., "Pasión y conocimiento. El amor por la verdad», Revista Zona Erógena, n 37, 1998.

[42] Vigotski, L.S., Imaginación y creación en la edad infantil, La Habana: Pueblo y Educación, 1987.

[43] Lovelock, J., Gaia. Una ciencia para curar el planeta, Barcelona: Integral, 1992.

[44] Pakman, M., «Introducción», de Introducción al Pensamiento complejo, Barcelona, Gedisa, 1998, pp. 9-16.

[45] Bateson, G., Pasos hacia una ecología de la mente, Buenos Aires: Lohlé-Lumen, 1985.

[46] Ribot, T., Imaginación creadora, París: Y.N. Erlich, 1901.

[47] Vigotski, L.S., El desarrollo de los procesos psíquicos superiores, Barcelona: Crítica, 1979.

[48] Vigotski, L.S., Historia de las funciones psíquicas superiores. Obras Escogidas. Tomo. III, Madrid: Visor, 2000.

[49] González-Rey, F., «El lugar de las emociones en la constitución social de lo psíquico: El aporte de Vigotski», Educação \& Sociedade, no. 70, pp. 132-148, 2000.

[50] García-Pérez, R., «Investigación educativa desde la perspectiva sociocultural». Tesis doctoral, Universidad de Sevilla, Sevilla, 2001.

[51] Freire, P., La educación como práctica de la libertad, Río de Janeiro: Paz y Tierra, 1983a.

[52] Rogoff, B., «Los tres planos de la actividad sociocultural: apropiación participativa, participación guiada y aprendizaje», de La mente sociocultural. Aproximaciones teóricas y aplicadas, Madrid, Fundación Infancia y Aprendizaje, 1997, pp. 111-128.

[53] Tudge, J. \& Rogoff, B., «Influencias entre iguales en el desarrollo cognitivo: perspectivas piagetiana y vigotskiana», de La interacción social en contextos educativos, Madrid, Siglo XXI, 1995, pp. 99-133.

[54] Wertsch, J.V., Vygotsky y la formación social de la mente, Barcelona: Paidós, 1988.

[55] Wertsch, J.V., «Semiotic mechanisms in joint cognitive activity», Infancia y Aprendizaje, no. 47, pp. 3-36, 1989.

[56] Wertsch, J.V., Voces de la mente, Madrid: Visor, 1993.

[57] Valsiner, J., «Modelos psicológicos, modelos educativos. Una perspectiva histórico-cultural», de Hacia un curriculum cultural. La vigencia de Vygotski en la educación, Madrid, Fundación Infancia y Aprendizaje, 1997, pp. 183-192.

[58] Solís, Y., «Propuesta Didáctica para el desarrollo de estrategias de aprendizaje con el apoyo de las Tecnologías de la Información y las Comunicaciones». Tesis doctoral, CUJAE, La Habana, 2004.

[59] Toffler, A., La tercera ola, Barcelona: Plaza \& Janes, S.A. Editores, 1980, p. 339.

[60] Thuillier, P., “¿Cómo se construyen las teorías científicas?,» Revista Humanidades, vol. 8, no. 8, 1977.

[61] Thompson, W. \& et al., Gaia: implicaciones de la nueva biología, Barcelona: Kairós, 1989.

[62] Snow, C.P., Las dos culturas y un segundo enfoque, Madrid: Alianza, 1977.

[63] Schön, D.A., La formación de profesores reflexivos, Madrid: Paidós, 1992.

[64] Romero-Pérez, C., «El constructivismo cibernético como metateoría educativa: aportaciones al estudio y regulación de los procesos de enseñanza y aprendizaje», Revista electrónica Teoría de la Educación de Universidad de Huelva no. 3, 2001. [En línea]. Disponible en http://www3.usal.es/ teoriaeducacion [Accedido: 23-jun-2018]

[65] Rodríguez, C., «Motivación de logro y satisfacción laboral». [En línea]. Disponible en: http:// www.semac.org.mx/congreso/6-2.pdf [Accedido: 12-jul-2018]

[66] Price, D.J., "Ciencia y tecnología: Distinciones e interrelaciones», de Estudios sobre sociología de la ciencia, Madrid, Alianza Universidad, 1980. 
[67] Piaget, J., La construcción de lo real en el niño, La Habana: Instituto Cubano del Libro, 1965.

[68] Ospina, J., «La motivación, motor del aprendizaje», Revista Ciencias de la Salud. Número especial de octubre, vol. 4, pp. 158-160, 2006.

[69] Núńez-Jover, J., La ciencia y la tecnología como procesos sociales, La Habana: "Félix Varela", 1999, p. 245.

[70] Núñez, J.C., "Motivación, aprendizaje y rendimiento académico», Actas do X Congresso Internacional Galego-Português de Psicopedagogia. Universidade do Minho, Braga, 2009.

[71] Novak, J.D., Conocimiento y Aprendizaje: los mapas conceptuales como herramientas facilitadoras para escuelas y empresas, Madrid: Alianza, 1998.

[72] Navarrete, B., «La motivación en el aula. Funciones del profesor para mejorar la motivación en el aprendizaje», Revista Innovación y experiencias pedagógicas. Granada, no. 15, 2009.

[73] Morin, E., Introducción al Pensamiento complejo, Barcelona: Gedisa, 1998a.

[74] Morin, E., Mis demonios. Autobiografía, Barcelona: Kairós, 1995a, p. 294.

[75] Martí, J., «Edison,» de Cuadernos Martianos. Martí y la Universidad, vol. 4, La Habana, Félix Varela, 1997, pp. 283-285.

[76] Martí, J., Edison. Obras escogidas en 3 tomos, vol. 2, La Habana: Ciencias Sociales, 1992, pp. 430-434.

[77] Martínez-Álvarez, F.F., «Fundamentos epistemológicos para la construcción de una Educación transdisciplinaria en Cuba». Tesis de Doctorado, Centro de Perfeccionamiento de la Educación Superior de la Universidad de La Habana. La Habana, 2011. [En línea]. Disponible en: http://revistas.mes.edu.cu/greenstone/collect/repo/index/assoc/D9789591/618771.dir/9789591618771. pdf

[78] Huertas, J.A., Motivación. Querer aprender, Aique: Buenos Aires, 1996.

[79] Gilbert, I., Motivar para aprender en el aula. Las siete claves de la motivación escolar, Barcelona: Paidós Educator, 2005.

[80] Dewey, J., Democracy and Education, New York: The Free Press., 1966.

[81] Cuenca, M. \& Rivero, M., "La modelación espacial: una posibilidad para potenciar el desarrollo metacognitivo en el Preescolar», de Selección de lecturas para educadoras, La Habana, Pueblo y Educación, 2006.

[82] Crane, D., Invisible Colleges, Chicago: University of Chicago Press, 1972.

[83] Alonso-Tapia, J., Motivar para el aprendizaje, Barcelona: Edebé, 1997. 